\section{A new compression pressure measuring device}

\author{
Yung-Wei Chi \\ Vascular Center, University of \\ California, Davis, CA, USA
}

\section{Introduction}

The sine qua non of compression therapy is interface pressure yet it is rarely measured in the routine care of patients. In 2006, the first International Compression Club consensus on an ideal sensor to measure interface pressure was published. ${ }^{1}$ In 2008 , the International Union of Phlebology (IUP) published a consensus document stating the lack of interface pressure measurement was a knowledge gap in compression therapy. ${ }^{2}$ The 2014 Society for Vascular Surgery and American Venous Forum (SVS-AVF) clinical guideline on venous ulcer care reiterated the lack of pressure measurement as a deficiency in the evidence to compression therapy. ${ }^{3}$ Moreover, in the 2015 IUP response to the SVS-AVF guideline, targeted pressure ranges were recommended for specific disease state. ${ }^{4}$ Yet interface pressure is seldom measured in routine ulcer care leaving most if not all compression therapy, arbitrary. After a decade from the initial call to action, manometer based devices such as PicoPress ${ }^{\circledR}$ (Microlab, Padua, Italy) and Kikuhime ${ }^{\circledR}$ (Meditrade, Soro, Denmark) are commercially available. Unfortunately, neither was widely adopted or used. The fact is the lack of this rudimentary information has raised concern from many healthcare and scientific entities including the Agency for Heathcare Research and Quality (AHRQ), the think-tank for U.S. healthcare policy. In the Jun 2016 AHRQ draft on Technology Assessment Report on Treatment Strategies for Patients with Lower Extremity Chronic Venous Disease, it clearly indicated two deficiencies related to compression therapy i) optimal pressure dosing and ii) duration of compression therapy. All existing and future interface pressure measuring devices will need to satisfy these two paucities.

\section{Materials and Methods}

From a technological stand-point, the mechanical properties of manometer, piezoresistive and capacitive based sensing characteristics are vastly different with pros and cons to each. In our work, a novel patented microfluidic capacitive (iontronic) sensor was developed, and was compared to the mechanical performance of PicoPress ${ }^{\circledR}{ }^{5}$ according to pressure cuff based cylinder model described previously by Partsch et al. ${ }^{6}$
Correspondence: Yung-Wei Chi, Vascular Center, University of California, Davis, CA, USA.

E-mail: ywchi@ucdavis.edu

This work is licensed under a Creative Commons Attribution 4.0 License (by-nc 4.0).

(C) Copyright Y.W. Chi, 2017

Licensee PAGEPress, Italy

Veins and Lymphatics 2017; 6:6636

doi:10.4081/vl.2017.6636

\section{Results}

After 10,000 cycle runs, the iontronic sensor demonstrated stability in both mechanical response and repeatability. In sensing characterization, both the iontronic sensor and PicoPress ${ }^{\circledR}$ showed complete overlap of pressure graphs against the standard pressure cuff model, $\mathrm{P}>0.05$ (Figure 1). ${ }^{5}$ In other words, the 2 sensors had the same sensing performance or efficacy.

\section{Conclusions}

Manometer based interface pressure measuring devices are available but future device innovation should focus on accuracy, versatility, user-friendliness, wireless communication and data collection including compliance tracking to ensure seamless adoption by healthcare providers and patients.

\section{References}

1. Partsch $\mathrm{H}$, Clark M, Bassez $\mathrm{S}$, et al. Measurement of lower leg compression in vivo: recommendations for the performance of measurements of interface pressure and stiffness: consensus statement. Dermatol Surg 2006;32:224-32; discussion 33.

2. Partsch H, Flour M, Smith PC; International Compression $\mathrm{C}$. Indications for compression therapy in venous and lymphatic disease consensus based on experimental data and scientific evidence. Under the auspices of the IUP. Int Angiol 2008;27:193-219.

3. O'Donnell TF Jr, Passman MA, Marston WA, et al. Management of venous leg ulcers: clinical practice guidelines of the Society for Vascular Surgery (R) and the American Venous Forum. J Vasc Surg 2014;60:3S-59S.

4. Mosti G, De Maeseneer M, Cavezzi A,

Figure 1. Iontronic sensor versus Picopress ${ }^{\circledR}$ performance characterization. 
et al. Society for Vascular Surgery and American Venous Forum Guidelines on the management of venous leg ulcers: the point of view of the International Union of Phlebology. Int Angiol
2015;34:202-18.

5. Li R, Nie B, Zhai C, et al. Telemedical wearable sensing platform for management of chronic venous disorder. Ann Biomed Eng 2016;44:2282-91.
6. Partsch H, Mosti G. Comparison of three portable instruments to measure compression pressure. Int Angiol 2010;29:426-30. 